\title{
Household- and employment-related risk factors for depressive symptoms during the COVID-19 pandemic
}

\author{
Christine M. Wickens ${ }^{1,2,3,4,5}$ (D) Hayley A. Hamilton ${ }^{1,2,3} \cdot$ Tara Elton-Marshall $^{1,2,3,6,7} \cdot$ Yeshambel T. Nigatu $^{1}$. \\ Damian Jankowicz ${ }^{1}$ • Samantha Wells ${ }^{1,2,3,6,8,9}$
}

Received: 11 June 2020 / Accepted: 28 December 2020 / Published online: 15 March 2021

(C) The Canadian Public Health Association 2021

\begin{abstract}
Objectives The COVID-19 pandemic has generated multiple psychological stressors, which may increase the prevalence of depressive symptoms. Utilizing Canadian survey data, this study assessed household- and employment-related risk factors for depressive symptoms during the pandemic.

Methods A sample of 1005 English-speaking Canadian adults aged 18+ years completed a web-based survey after physical distancing measures were implemented across Canada. Hierarchical binary logistic regression analyses were conducted to examine the associations of depressive symptoms with household- (household size, presence of children, residence locale) and employment-related (job with high risk of COVID-19 exposure, working from home, laid off/not working, financial worry) risk factors, controlling for demographic factors (gender, age, education, income).

Results About $20.4 \%$ of the sample reported depressive symptoms at least 3 days per week. The odds of experiencing depressive symptoms $3+$ days in the past week were higher among women (AOR $=1.67, p=0.002)$ and younger adults $(18-29$ years $\mathrm{AOR}=2.62, p<0.001)$. After adjusting for demographic variables, the odds of experiencing depressive symptoms were higher in households with $4+$ persons $(\mathrm{AOR}=1.88, p=0.01)$, in households with children aged 6 to 12 years $(\mathrm{AOR}=1.98, p=0.02)$, among those with a job at high risk for exposure to COVID-19 (AOR $=1.82, p=0.01$ ), and those experiencing financial worry due to COVID-19 ('very worried' AOR $=8.00, p<0.001$ ).

Conclusion Pandemic responses must include resources for mental health interventions. Additionally, further research is needed to track mental health trajectories and inform the development, targeting, and implementation of appropriate mental health prevention and treatment interventions.
\end{abstract}

\section{Résumé}

Objectif La pandémie de COVID-19 a engendré de multiples facteurs de stress psychologique qui peuvent faire augmenter la prévalence des symptômes de dépression. Cette étude se fonde sur les résultats de sondages auprès de Canadien.ne.s pour évaluer les facteurs de risque liés à l'emploi et dans les ménages qui prédisposent aux symptômes de dépression pendant la pandémie.

Christine M. Wickens

Christine.Wickens@camh.ca

1 Institute for Mental Health Policy Research, Centre for Addiction and Mental Health, 33 Ursula Franklin Street, Toronto, Ontario M5S 2S1, Canada

2 Campbell Family Mental Health Research Institute, Centre for Addiction and Mental Health, Toronto, Ontario, Canada

3 Dalla Lana School of Public Health, University of Toronto, Toronto, Ontario, Canada

4 Institute of Health Policy, Management and Evaluation, University of Toronto, Toronto, Ontario, Canada
5 Department of Pharmacology and Toxicology, University of Toronto, Toronto, Ontario, Canada

6 Department of Epidemiology and Biostatistics, Schulich School of Medicine and Dentistry, Western University, London, Ontario, Canada

7 Department of Health Sciences, Lakehead University, Thunder Bay, Ontario, Canada

8 Department of Psychiatry, University of Toronto, Toronto, Ontario, Canada

9 School of Psychology, Deakin University, Burwood, Victoria, Australia 
Méthode Un échantillon de 1005 Canadien.ne.s anglophones âgé.e.s de 18 ans ou plus ont rempli un sondage en ligne après l'imposition des mesures de distanciation physique partout au Canada. Une analyse de régression logistique binaire de type hiérarchique a permis d'établir les liens entre les symptômes de dépression et certains facteurs de risque dans les ménages (nombre de membres, présence d'enfants, localité de la résidence) ainsi que des facteurs de risque liés à l'emploi (emploi comportant un risque élevé d'exposition à la COVID-19, télétravail, mise à pied ou chômage, soucis financiers), après un contrôle des facteurs démographiques (sexe, âge, niveau d'éducation, revenu).

Résultats Environ 20,4 \% des répondant.e.s ont dit avoir eu des symptômes de dépression au moins trois jours par semaine. La probabilité d'avoir des symptômes de dépression trois jours ou plus au cours de la semaine écoulée est plus élevée pour les femmes (rapport de cotes ajusté, ou RCA = 1,67, $p=0,002)$ et les jeunes adultes (18 à 29 ans, $\mathrm{RCA}=2,62, p<0,001)$. Après réajustement des variables démographiques, cette probabilité est plus élevée pour les ménages de quatre personnes ou plus (RCA $=1,88, p=0,01)$ et ceux ayant des enfants de 6 à 12 ans $(\mathrm{RCA}=1,98, p=0,02)$, ainsi que pour les personnes dont l'emploi comporte un risque élevé d'exposition à la COVID-19 ( $\mathrm{RCA}=1,82, p=0,01)$, et celles éprouvant des soucis financiers à cause de la COVID-19 ( « très inquiet », RCA $=8,00, p<0,001$ ).

Conclusion Les ressources d'intervention en santé mentale doivent faire partie des mesures de lutte contre la pandémie. De plus, des recherches approfondies s'imposent afin de suivre l'évolution de la santé mentale des Canadien.ne.s et de guider l'élaboration, le ciblage et la mise en œuvre de mesures appropriées de prévention et de traitement des problèmes de santé mentale.

Keywords COVID-19 $\cdot$ Depression $\cdot$ Risk factors $\cdot$ Stress, psychological $\cdot$ Family characteristics $\cdot$ Employment

Mots-clés COVID-19 $\cdot$ dépression $\cdot$ facteurs de risque $\cdot$ stress psychologique $\cdot$ caractéristiques familiales $\cdot$ emploi

\section{Introduction}

In March 2020, the World Health Organization (WHO) declared COVID-19 a pandemic. In countries worldwide, public health measures were introduced to limit spread of the virus, including stay-at-home directives and shutdowns of schools, community gathering places, and non-essential businesses. Despite these measures, by mid-May, there were more than 4 million cases worldwide and close to 300,000 deaths; as of September 1, there were more than 25 million cases and close to 850,000 deaths (WHO 2020).

The COVID-19 pandemic and public health restrictions are creating a multitude of stressors, including household- and employment-related factors. Many people are experiencing stress related to essential frontline work and the risk of becoming infected (Hyland et al. 2020). Millions of workers who previously commuted to an external workplace now find themselves working from home (Statistics Canada 2020a, b). This shift may present new challenges, including work-family balance, difficulty with information technology, and finding new ways to do previously routine tasks, all of which might contribute to elevated stress. In early June, $74 \%$ of parents surveyed in Canada reported feeling very or extremely concerned about balancing childcare, schooling, and work (Statistics Canada 2020c). A large number of Canadians also find themselves without paid employment, with no available shifts or with layoff notices (TransUnion 2020). Many Canadians, and even those who are still working, have worries about the financial impact of the pandemic. In early May, 59\% of Canadian consumers reported that their income had been negatively impacted by the pandemic (TransUnion 2020).
A growing body of research indicates that psychological stress can induce physiological responses in multiple systems within the body (e.g., nervous, endocrine, and immune systems) which can ultimately result in harm, including depression (Yang et al. 2015). Depression has been identified as a leading cause of disability (Friedrich 2017) and is, therefore, a key public health concern. Given the many stressors associated with the COVID-19 pandemic, it is important to assess their associations with depressive symptoms.

Research on prior outbreaks, including the severe acute respiratory syndrome (SARS) epidemic and the H1N1 pandemic, has indicated that employment-related and household factors may increase psychosocial stress and mental health outcomes. Healthcare workers who treated patients affected by SARS experienced frustration, fear of infection and transmission of the virus to others, and stigma in their communities (Nickell et al. 2004) and those subjected to quarantine measures reported exhaustion, irritability, insomnia, detachment from others, and deteriorating work performance (Bai et al. 2004). Studies indicated that women and people with lower educational attainment were especially likely to experience psychological distress and symptoms of post-traumatic stress during disease outbreaks (e.g., Peng et al. 2010; Xu et al. 2011). Research also suggested that young people may be at greater risk of psychological distress than older people (e.g., Peng et al. 2010; Wang et al. 2020); however, other studies found elderly people were at greater risk of reporting an adverse impact of the outbreak on their mental health (e.g., Lau et al. 2005). During the SARS crisis in Toronto, those quarantined who had household incomes below $\$ 40,000$ (CAD) experienced more depressive symptoms than those with higher incomes (Hawryluck et al. 2004). 
The sheer magnitude of the COVID-19 pandemic may make it difficult to generalize results from historical studies to current times. Research conducted during prior infectious disease outbreaks often focused on select groups (e.g., affected patients, healthcare workers, people who had been quarantined) (Bai et al. 2004; Mak et al. 2009; Nickell et al. 2004), with fewer studies focused on broader general-population samples (e.g., Peng et al. 2010). In contrast, the public health measures implemented to limit the spread of COVID-19 (physical distancing, stay-at-home directive, quarantine) along with the closure of nonessential businesses have affected all segments of the population and may have very different and potentially more detrimental effects on mental health than has been found before.

Surveys documenting mental health consequences of COVID19 are starting to emerge from countries globally, many identifying specific groups who may be more vulnerable to psychological sequelae of the pandemic. These at-risk groups include women, younger age cohorts (Bäuerle et al. 2020; Hyland et al. 2020; Wang et al. 2020), individuals with economic instability or lower income (Taylor et al. 2020), individuals with loss of income due to the pandemic (Hyland et al. 2020), those living with others (Wang et al. 2020), and those who perceive higher risk of COVID-19 infection (Hyland et al. 2020). A number of household-related factors may be linked to depressive symptoms. For example, preliminary evidence suggests that depressive symptoms may be positively associated with household size (Wang et al. 2020), with the presence of school-age children in the home posing challenges to many parents who are working from home (Statistics Canada 2020c). Urban versus rural residence location may also affect people's mental health during isolation. In urban centres, where population density is high and available green space is limited, abiding by physical distancing measures may be a challenge when venturing out. As a result, those living in urban centres may have less access to the outdoors and may experience greater mental health impacts of pandemic-related public health interventions (Slater et al. 2020).

The objective of this study was to examine household- (i.e., household size, presence of children, and residence locale) and employment-related (i.e., job exposure to risk of getting COVID-19, change in employment situation, and worry about the impact of COVID-19 on personal finances) risk factors for depressive symptoms among the Canadian population during the COVID-19 pandemic. This information will be useful for developing and targeting interventions to address mental health challenges during major disease outbreaks.

\section{Methods}

\section{Sample and procedures}

A sample of 1005 Canadian adults aged $18+$ years responded to a web-based survey between May 8 and 12, 2020.
Participants were members of the AskingCanadians web panel hosted by Delvinia (data are publicly available: http://www. delvinia.com/camh-coronavirus-mental-health/). Sampling quotas for age, gender, and region (categorized into 6 regions: British Columbia, Alberta, Saskatchewan and Manitoba, Ontario, Quebec, and the Atlantic provinces, and the territories including Yukon, Nunavut, and the Northwest Territories) were designed to approximate proportionality to the Canadian English-speaking population. Informed consent was obtained electronically prior to the start of the survey. The study was approved by the Research Ethics Board at the Centre for Addiction and Mental Health.

\section{Materials}

Depressive symptoms Due to survey length restrictions, the experience of depressive symptoms was measured with a single item from the Center for Epidemiologic Studies Depression Scale (CES-D; Radloff 1977): 'In the past 7 days, how often have you felt depressed?' Response options included 'rarely or none of the time (less than 1 day)', 'some or a little of the time (1-2 days)', 'occasionally or a moderate amount of the time (3-4 days)', and 'most or all of the time (5-7 days)'. Responses were converted to binary coding to allow for comparison of those who reported feeling depressed occasionally/moderately to all of the time (i.e., between 3 and 7 days per week) with those who reported feeling depressed rarely/none of the time to some or a little of the time (i.e., less than 3 days per week). This allowed a focus on those higherrisk individuals who reported depressive symptoms at least half of the time.

Household risk factors Household risk factors included number of persons living in the household (1 or 2, 3, 4+ persons), the presence of children under the age of 6 years (no, yes), the presence of children between the ages of 6 and 12 years (no, yes), and residence locale (urban, suburban, rural).

Employment-related risk factors Employment-related risk factors included whether or not the individual reported having a job that exposes them to high risk of getting COVID-19 (i.e., job exposure; no, yes); if they had experienced a change in their employment situation (working from home, laid off or not working, no change or other); and worry about the impact of COVID-19 on their personal financial situation. The latter item was originally rated on a 4-point Likert-type scale, but was recoded to a 3-point scale due to low numbers in the lowest category (not at all to not very worried, somewhat worried, very worried).

Demographics Demographic variables included sex (woman, man), age (18-29, 30-39, 40-49, 50-59, 60+ years), education (less than university degree, university degree), and 
income (less than $\$ 40,000, \$ 40,000-\$ 79,999$, $\$ 80,000-\$ 119,999, \$ 120,000+$, prefer not to answer).

\section{Statistical analyses}

To assess bivariate associations, chi-square analyses examined prevalence of depressive symptoms by demographic-, household-, and employment-related risk factors. After an initial binary logistic regression analysis assessing demographic risk factors for depressive symptoms, two hierarchical binary logistic regression analyses were conducted to examine the effects of household risk factors and employment-related risk factors, adjusting for demographic variables. Missing values were excluded from analyses using listwise deletion. Adjusted odds ratios (AOR) and 95\% confidence intervals $(95 \% \mathrm{CI})$ were obtained from logistic regression models. $p$ values of less than 0.05 were considered to be statistically significant. All analyses were conducted using SPSS v25 software.

\section{Results}

Approximately $20.4 \%$ of the sample reported feeling depressed at least 3 days per week. Table 1 presents selfreported depressive symptoms by demographic-, household-, and employment-related risk factors. Based on chi-square analyses, depressive symptoms were significantly more prevalent among women, among those who were younger, residing in households with 4+ persons, residing in households with children under age 6 years and children aged 6 to 12 years, in a job with high risk of exposure to COVID-19, laid off or not working due to COVID-19, and among those experiencing financial worry due to COVID-19.

The first multiple logistic regression model included the demographic variables (see Table 2). The odds of feeling depressed 3+ days in the past week were higher among women than among men $(\mathrm{AOR}=1.67,95 \% \mathrm{CI}=1.21,2.30, p=$ 0.002 ) and among all age groups compared to those $60+$ years of age, with highest adjusted odds reported for respondents aged 18 to 29 years $(\mathrm{AOR}=2.62,95 \% \mathrm{CI}=1.57,4.36$, $p<0.001)$.

The second model included household risk factors, specifically household size and composition and residence locale, controlling for demographic variables (see Table 2). In order to assess both household size and presence of children in the same model, the reference category for household size combined the 1-person and 2-person categories. After adjusting for demographic variables, the odds of experiencing depressive symptoms were higher in households with 4+ persons $(\mathrm{AOR}=1.88,95 \% \mathrm{CI}=1.14,3.12, p=0.01)$ and in households with children aged 6 to 12 years $(\mathrm{AOR}=1.98,95 \%$ $\mathrm{CI}=1.12,3.49, p=0.02$ ).
The final model included risk factors associated with employment, controlling for the demographic variables (see Table 2). After adjusting for demographic variables, the odds of experiencing depressive symptoms were higher among those with a job at high risk for exposure to COVID-19 $(\mathrm{AOR}=1.82,95 \% \mathrm{CI}=1.15,2.88, p=0.01)$ and those experiencing financial worry due to COVID-19, with the highest adjusted odds reported by respondents who selfidentified as being very worried about the financial impact of the crisis $(\mathrm{AOR}=8.00,95 \% \mathrm{CI}=4.70,13.61, p<0.001)$.

\section{Discussion}

There is growing evidence to suggest that stressors associated with the COVID-19 pandemic are resulting in increased prevalence of mental health problems. A recent study of Canadians conducted during the pandemic indicated that $24 \%$ of the sample described their mental health as poor or fair, $31 \%$ as good, and $46 \%$ as very good (Statistics Canada 2020d). In contrast, the 2018 Canadian Community Health Survey (CCHS) found that $8 \%$ of the sample described their mental health as poor or fair, $24 \%$ as good, and $69 \%$ as very good. Although data for the Statistics Canada study did not use a probability sample and therefore should not be used to draw inferences about the broader Canadian population, comparison to the CCHS 2018 data suggests that the pandemic has had a significant negative impact on the mental health of Canadians. Similar findings have been reported globally (e.g., Bäuerle et al. 2020; Zhou et al. 2020). Consistent with this evidence, the current study, conducted between May 8 and 12,2020 , approximately 8 weeks after the implementation of significant public health restrictions across Canada, found that about $20.4 \%$ of the sample reported depressive symptoms on at least 3 of the previous 7 days.

After adjusting for demographic variables, larger household size was associated with a greater likelihood of having depressive symptoms. Compared to individuals living in a 1- or 2-person household, those living in a household with 4 or more persons were more likely to experience depressive symptoms. This finding would seem to run contrary to concerns that loneliness associated with self-isolation might result in increased rates of depression (Armitage and Nellums 2020). Instead, it appeared that having more individuals in the household constituted a potential stressor. It may be that after weeks of a stay-at-home directive, nerves may fray or tempers may run short, reducing the potential benefits of social support and camaraderie from other household members. Still, loneliness may be an important consideration for future analyses; continued separation from friends and family outside the home and from co-workers previously seen on a daily basis may contribute to feelings of loneliness, even in multiperson households. The decision to collapse the 1- and 2-person households into a single category in the regression 
Table 1 Depressive symptoms (feeling depressed 3+ days in past week) by demographic-, household-, and employment-related risk factors among Canadian English-speaking adults aged $18+$ years $(n=1005)$

\begin{tabular}{|c|c|c|c|c|c|}
\hline & \multirow[t]{3}{*}{ Total $N$} & \multicolumn{4}{|c|}{ Depressive symptoms } \\
\hline & & \multicolumn{2}{|l|}{ Yes } & \multicolumn{2}{|l|}{ No } \\
\hline & & $N$ & $(\%)$ & $N$ & $(\%)$ \\
\hline \multicolumn{6}{|l|}{ Demographic risk factors } \\
\hline Gender** & 1002 & & & & \\
\hline Man & 504 & 82 & $(16.3)$ & 422 & $(83.7)$ \\
\hline Woman & 498 & 122 & $(24.5)$ & 376 & $(75.5)$ \\
\hline $\mathrm{Age}^{* *}$ & 1005 & & & & \\
\hline $18-29$ years & 132 & 38 & $(28.8)$ & 94 & $(71.2)$ \\
\hline $30-39$ years & 262 & 58 & $(22.1)$ & 204 & $(77.9)$ \\
\hline $40-49$ years & 129 & 28 & $(21.7)$ & 101 & $(78.3)$ \\
\hline $50-59$ years & 177 & 41 & $(23.2)$ & 136 & $(76.8)$ \\
\hline $60+$ years & 305 & 40 & $(13.1)$ & 265 & $(86.9)$ \\
\hline Education & 998 & & & & \\
\hline Less than university degree & 460 & 102 & $(22.2)$ & 358 & $(77.8)$ \\
\hline University degree & 538 & 103 & $(19.1)$ & 435 & $(80.9)$ \\
\hline Income & 1005 & & & & \\
\hline Less than $\$ 40,000$ & 128 & 32 & $(25.0)$ & 96 & $(75.0)$ \\
\hline$\$ 40,000-\$ 79,999$ & 268 & 57 & $(21.3)$ & 211 & $(78.7)$ \\
\hline$\$ 80,000-\$ 119,999$ & 226 & 49 & $(21.7)$ & 177 & $(78.3)$ \\
\hline$\$ 120,000+$ & 217 & 38 & $(17.5)$ & 179 & $(82.5)$ \\
\hline Prefer not to answer & 166 & 29 & $(17.5)$ & 137 & $(82.5)$ \\
\hline \multicolumn{6}{|l|}{ Household risk factors } \\
\hline Household size $\mathrm{a}_{* * *}$ & 1005 & & & & \\
\hline 1 person & 205 & 40 & $(19.5)$ & 165 & $(80.5)$ \\
\hline 2 persons & 406 & 59 & $(14.5)$ & 347 & $(85.5)$ \\
\hline 3 persons & 176 & 42 & $(23.9)$ & 134 & $(76.1)$ \\
\hline $4+$ persons & 218 & 64 & (29.4) & 154 & $(70.6)$ \\
\hline Presence of children under 6 years of age* & 779 & & & & \\
\hline No & 668 & 127 & $(19.0)$ & 541 & $(81.0)$ \\
\hline Yes & 111 & 31 & $(27.9)$ & 80 & $(72.1)$ \\
\hline Presence of children aged 6-12 years of age*** & 779 & & & & \\
\hline No & 688 & 126 & $(18.3)$ & 562 & $(81.7)$ \\
\hline Yes & 91 & 32 & $(35.2)$ & 59 & $(64.8)$ \\
\hline Residence locale & 1005 & & & & \\
\hline Urban & 465 & 106 & $(22.8)$ & 359 & $(77.2)$ \\
\hline Suburban & 382 & 75 & $(19.6)$ & 307 & $(80.4)$ \\
\hline Rural & 158 & 24 & $(15.2)$ & 134 & $(84.8)$ \\
\hline \multicolumn{6}{|l|}{ Employment-related risk factors } \\
\hline Job exposure to COVID-19** & 1005 & & & & \\
\hline No & 880 & 166 & $(18.9)$ & 714 & $(81.1)$ \\
\hline Yes & 125 & 39 & $(31.2)$ & 86 & $(68.8)$ \\
\hline Employment impact* & 1005 & & & & \\
\hline Working from home & 255 & 52 & $(20.4)$ & 203 & $(79.6)$ \\
\hline Laid off, not working & 172 & 49 & $(28.5)$ & 123 & $(71.5)$ \\
\hline No change, other & 578 & 104 & $(18.0)$ & 474 & $(82.0)$ \\
\hline Financial worry due to COVID-19*** & 1005 & & & & \\
\hline Not at all to not very worried & 310 & 22 & $(7.1)$ & 288 & $(92.9)$ \\
\hline
\end{tabular}


Table 1 (continued)

\begin{tabular}{|c|c|c|c|c|c|}
\hline & \multirow[t]{3}{*}{ Total $N$} & \multicolumn{4}{|c|}{ Depressive symptoms } \\
\hline & & \multicolumn{2}{|c|}{ Yes } & \multicolumn{2}{|l|}{ No } \\
\hline & & $N$ & $(\%)$ & $N$ & $(\%)$ \\
\hline Somewhat worried & 475 & 97 & (20.4) & 378 & (79.6) \\
\hline Very worried & 220 & 86 & $(39.1)$ & 134 & $(60.9)$ \\
\hline
\end{tabular}

Chi-square statistical significance $* p<0.05 ; * * p<0.01 ; * * * p<0.001$

${ }^{a}$ In the binary logistic regression analysis, 1- and 2-person households were collapsed into a single category to accommodate the assessment of children in the household as a predictor of feeling depressed. A chi-square analysis of household size with 1- and 2-person households collapsed into a single category also generated a significant finding, $\chi(2)=18.70, p<0.001$

analysis was made to accommodate the inclusion of variables reflecting the presence of children in the household, which by necessity would not include single-person households. We tested a model with the 1-person household as the reference category, without the inclusion of the child-related variables, and the findings for household size were the same. Households with 4+ persons faced greater odds of feeling depressed compared to 1-person households; no other comparisons were statistically significant (results not shown).

The current study also assessed whether the presence of young children in the household was associated with depressive symptoms. Although results of the chi-square analyses suggested that the presence of both children under 6 years of age and children aged 6 to 12 years were associated with greater risk for depressive symptoms, only the presence of children aged 6 to 12 years was a significant explanatory factor in the adjusted model. With schools closed, many parents of schoolaged children are now responsible for delivering school curriculum to their children at home, juggling these responsibilities with employment and other homecare responsibilities. The resulting workload may leave parents of school-aged children particularly stressed and vulnerable to depressive symptoms.

In terms of the physical environment in which the household is situated, the prevalence of depressive symptoms was lower among people residing in rural compared with urban areas. Previous research has identified a lower risk of depression among rural dwellers, citing a stronger sense of community belonging as being a protective factor (Romans et al. 2011). During the COVID-19 crisis, the availability of open space for recreation and lower incidence of the virus in rural communities may also be contributing to this trend.

Individuals who reported having a job that put them at high risk for exposure to COVID-19 were at increased risk for depressive symptoms. This finding may reflect heightened stress and chronic awareness and caution required on the job in high-risk environments as well as increased hours for frontline workers. Results of the chi-square analyses suggested that being laid off or not working, and being worried about the impact of COVID-19 on one's personal financial situation, were associated with increased risk of depressive symptoms. However, in the multivariate model, only financial worry was a statistically significant explanatory factor. The inclusion of both variables in the same model may have resulted in overlap in accounted variance. Financial worry was also significant and positively associated with depressive symptoms. Thus, financial worry for many people during this time of crisis may be an important risk factor for depressive symptoms.

Consistent with pre-pandemic data (Kessler et al. 2010; National Institute of Mental Health 2019) and with recent reports from several other countries during the pandemic (e.g., Bäuerle et al. 2020; Hyland et al. 2020; Wang et al. 2020), the current survey indicates that women and younger individuals may be at greater risk for depressive symptoms. These results were significant even after adjusting for differences in education and income. Increased vulnerability to depression among women has been considered from biological, social, and cultural perspectives. For example, women often work outside the home but are also the persons primarily tasked with home, childcare, and senior care responsibilities, resulting in work overload (Nolen-Hoeksema et al. 1999). Young people may be experiencing heightened stress in relation to achieving milestones of emerging adulthood (e.g., moving away from the childhood home, choosing a career path; Berry 2004), given school university/college closures, uncertainties around employment, and effects of the pandemic on their social lives.

It is important to acknowledge limitations of this research. The data were correlational; thus, no causal inferences can be drawn. As a web-based survey, this study excluded potential respondents with limited knowledge of or access to Internet technology; however, the most recent data from Statistics Canada (2019) indicate that $94 \%$ of Canadians have home Internet access, reducing the potential bias associated with use of a web-based platform. The survey may also have been subject to non-response bias; it cannot be determined whether eligible respondents who declined to give consent to participate would have provided data similar to that collected from individuals who consented to participate. Urban density in the 
Table 2 Binary logistic regression models of depressive symptoms (feeling depressed 3+ days in the past week) among Canadian English-speaking adults aged $18+$ years

\begin{tabular}{|c|c|c|c|c|c|c|}
\hline & \multicolumn{6}{|c|}{ Depressive symptoms } \\
\hline & \multicolumn{2}{|c|}{$\begin{array}{l}\text { Demographic risk } \\
\text { factors model }(n=995)\end{array}$} & \multicolumn{2}{|c|}{$\begin{array}{l}\text { Household risk factors } \\
\text { model }(n=770)\end{array}$} & \multicolumn{2}{|c|}{$\begin{array}{l}\text { Employment-related risk } \\
\text { factors model }(n=995)\end{array}$} \\
\hline & $\operatorname{Adj} \mathrm{OR}^{\mathrm{a}}$ & $95 \% \mathrm{CI}^{\mathrm{b}}$ & Adj $\mathrm{OR}^{\mathrm{a}}$ & $95 \% \mathrm{Cl}^{\mathrm{b}}$ & Adj $\mathrm{OR}^{\mathrm{a}}$ & $95 \% \mathrm{CI}^{\mathrm{b}}$ \\
\hline \multicolumn{7}{|l|}{ Demographic risk factors } \\
\hline Gender $(\mathrm{ref}=\mathrm{man})$ & $1.67 * *$ & $1.21,2.30$ & 1.37 & $0.94,1.98$ & $1.62 * *$ & $1.15,2.27$ \\
\hline Age (ref $=60+$ years $)$ & $* *$ & & $*$ & & $*$ & \\
\hline $18-29$ years & $2.62 * * *$ & $1.57,4.36$ & $2.46^{* *}$ & $1.29,4.68$ & $2.38 * *$ & $1.38,4.11$ \\
\hline $30-39$ years & $2.12 * *$ & $1.34,3.35$ & 1.56 & $0.85,2.89$ & $1.67 *$ & $1.01,2.72$ \\
\hline $40-49$ years & $1.98^{*}$ & $1.15,3.40$ & 1.19 & $0.57,2.46$ & 1.57 & $0.88,2.80$ \\
\hline $50-59$ years & $1.91 * *$ & $1.17,3.12$ & $2.14 *$ & $1.17,3.93$ & 1.57 & $0.93,2.66$ \\
\hline Education (ref=less than university) & 0.83 & $0.60,1.15$ & 0.74 & $0.50,1.08$ & 0.85 & $0.60,1.20$ \\
\hline \multicolumn{7}{|l|}{ Income (ref=less than $\$ 40,000)$} \\
\hline$\$ 40,000-\$ 79,999$ & 0.87 & $0.52,1.45$ & 0.59 & $0.30,1.16$ & 0.83 & $0.49,1.42$ \\
\hline$\$ 80,000-\$ 119,999$ & 0.90 & $0.53,1.52$ & 0.75 & $0.38,1.47$ & 0.93 & $0.53,1.64$ \\
\hline$\$ 120,000+$ & 0.66 & $0.38,1.15$ & 0.52 & $0.27,1.03$ & 0.74 & $0.41,1.34$ \\
\hline Prefer not to answer & 0.70 & $0.39,1.26$ & 0.58 & $0.28,1.21$ & 0.21 & $0.36,1.25$ \\
\hline \multicolumn{7}{|l|}{ Household risk factors } \\
\hline Household size (ref=1 or 2 persons) & & & $*$ & & & \\
\hline 3 persons & - & - & 1.55 & $0.94,2.56$ & - & - \\
\hline 4 persons & - & - & $1.88^{*}$ & $1.14,3.12$ & - & - \\
\hline Presence of children under 6 years of age $(r e f=n o)$ & - & - & 1.24 & $0.71,2.14$ & - & - \\
\hline Presence of children aged 6-12 years of age $(\mathrm{ref}=\mathrm{no})$ & - & - & $1.98 *$ & $1.12,3.49$ & - & - \\
\hline \multicolumn{7}{|l|}{ Residence locale (ref=urban) } \\
\hline Suburban & - & - & 0.75 & $0.50,1.12$ & - & - \\
\hline Rural & - & - & $0.54 *$ & $0.30,0.97$ & - & - \\
\hline \multicolumn{7}{|l|}{ Employment-related risk factors } \\
\hline Job exposure to COVID-19 (ref=no) & - & - & - & - & $1.82 *$ & $1.15,2.88$ \\
\hline \multicolumn{7}{|l|}{ Employment impact (ref=no change/other) } \\
\hline Working from home & - & - & - & - & 1.16 & $0.75,1.77$ \\
\hline Laid off, not working & - & - & - & - & 1.08 & $0.70,1.67$ \\
\hline Financial worry due to COVID-19 (ref=not at all to not very worried) & & & & & $* * *$ & \\
\hline Somewhat worried & - & - & - & - & $3.14 * * *$ & $1.91,5.16$ \\
\hline Very worried & - & - & - & - & $8.00 * * *$ & $4.70,13.61$ \\
\hline Constant & $0.15^{* * *}$ & & $0.20 * * *$ & & $0.05^{* * *}$ & \\
\hline Hosmer and Lemeshow test & $4.51_{(8 \mathrm{df})}$ & $p=0.81$ & $4.64_{(8 \mathrm{df})}$ & $p=0.80$ & $12.10_{(8 \mathrm{df})}$ & $p=0.15$ \\
\hline
\end{tabular}

${ }^{\mathrm{a}}$ Adjusted odds ratio

b $95 \%$ confidence intervals

Wald statistical significance $* p<0.05 ; * p<0.01 ; * * p<0.001$

current study was based on subjective self-report as opposed to an objective geographical measure, but future research should explore this risk factor further. Finally, the primary outcome variable was a single item taken from a wellvalidated measure (i.e., the CES-D) designed only to screen for depression; this item is not a diagnostic measure. The item was dichotomized in the current analysis in order to focus on individuals who were experiencing depressive symptoms at least half of the time; it is not possible to determine whether these individuals would be diagnosed with depression.

\section{Conclusion}

There has been much discussion of the potential mental health impact of COVID-19, the urgency of needs assessment, and 
proactive resource allocation in the context of the pandemic (Holmes et al. 2020). The data presented here and the growing body of evidence being collected globally clearly indicate that the COVID-19 pandemic is significantly impacting people's mental health. For this reason, it is essential that our response to the pandemic includes resources for mental health prevention and interventions. The current data also identify specific groups who may be more vulnerable to adverse mental health impacts of the pandemic and for whom intervention strategies should be targeted. Young people and families with children aged 6 to 12 years of age appear to be particularly vulnerable. Perhaps public health messaging and advertising of mental health resources through social media would be an effective strategy in targeting youth, and development of school- or community-based programs could target families with young children. Similarly, employees whose jobs put them at high risk for exposure to COVID-19 may be more vulnerable to depressive symptoms. Thus, for workplaces involving frontline work, employers, industry associations, or labour unions may improve employee mental health by providing or promoting mental health resources to employees or members. Financial distress was also significantly related to depressive symptoms. Government assistance and economic stimulus programs may be needed to reduce the mental health impact of COVID-19 on lower socio-economic status groups.

More broadly, we must reinforce the mental health system by planning appropriately for the growing need for mental health services, increasing capacity of the mental health system, and facilitating access to services through more connections with primary and emergency care. Monitoring ongoing use and capacity of the mental health system and identifying and addressing gaps in service must be prioritized. Spurred by the onset of the stay-at-home directive associated with COVID-19, online resources, digital mental health, and telemedicine have rapidly become essential to delivery of mental healthcare services in countries around the world (Zhou et al. 2020). This rapid transformation of service delivery and the provision of alternative sources of support are greatly needed to expand mental healthcare services; however, these sources of support should be subject to evaluation of their efficacy, acceptability, and accessibility among all vulnerable groups identified in the current study.

Finally, surveillance of mental health, including depressive symptoms, throughout the pandemic will be vital to track trajectories over time and to better understand the complex interrelationships between risk factors and depressive symptoms. As more data become available across Canada and the world, comparisons across jurisdictions will be possible and can be assessed as a function of both COVID-19 risk exposure and public health response. As indicated by the current study, surveillance of the mental health impact of the virus must focus not only on the broader general population but also on specific groups who are more vulnerable to this impact. It is also essential that future research assess the mechanisms underlying each vulnerability to mental health impacts of COVID-19 in order to maximize efficacy of prevention and treatment interventions. This and future surveys like it will continue to serve as tools to track mental health in jurisdictions worldwide in order to inform development, targeting, and implementation of mental health prevention and treatment interventions as we continue to work 'Together Alone' through COVID-19.

Authors' contributions Conceptualization: HAH, TEM, SW, DJ; methodology: HAH, TEM, SW, CMW, YTN; data curation: YTN; formal analysis: CMW; writing — original draft: CMW; writing - review and editing: all authors; project administration: HAH, TEM.

Funding The researchers acknowledge in-kind support for data collection by Delvinia.

\section{Compliance with ethical standards}

Conflict of interest The authors have no competing interests.

\section{References}

Armitage, R., \& Nellums, L. B. (2020). COVID-19 and the consequences of isolating the elderly. The Lancet Public Health, 5(5), e256.

Bai, Y., Lin, C.-C., Lin, C.-Y., Chen, J.-Y., Chue, C.-M., \& Chou, P. (2004). Survey of stress reactions among healthcare workers involved with the SARS outbreak. Psychiatric Services, 55, 10551057.

Bäuerle, A., Teufel, M., Musche, V., Weismüller, B., Kohler, H., Hetkamp, M., et al. (2020). Increased generalized anxiety, depression and distress during the COVID-19 pandemic: a cross-sectional study in Germany. Journal of Public Health (Oxford), 42(4), 672678.

Berry, D. (2004). The relationship between depression and emerging adulthood: theory generation. Advances in Nursing Science, 27(1), 53-69.

Friedrich, M. J. (2017). Depression is the leading cause of disability around the world. JAMA, 317(15), 1517.

Hawryluck, L., Gold, W. L., Robinson, S., Pogorski, S., Galea, S., \& Styra, R. (2004). SARS control and psychological effects of quarantine, Toronto, Canada. Emerging Infectious Diseases, 10, 1206 1212 www.cdc.gov/eid.

Holmes, E. A., O'Connor, R. C., Perry, V. H., Tracey, I., Wessely, S., Arsenault, L., et al. (2020). Multidisciplinary research priorities for the COVID-19 pandemic: a call for action for mental health science. Lancet Psychiatry, 7, 547-560.

Hyland, P., Shevlin, M., McBride, O., Murphy, J., Karatzias, T., Bentall, R. P., et al. (2020). Anxiety and depression in the Republic of Ireland during the COVID-19 pandemic. Acta Psychiatrica Scandinavica, 142, 249-256.

Kessler, R. C., Birnbaum, H., Bromet, E., Hwang, I., Sampson, N., \& Shahly, V. (2010). Age differences in major depression: results from the National Comorbidity Survey Replication (NCS-R). Psychological Medicine, 40, 225-237.

Lau, J. T. F., Yang, X., Pang, E., Tsui, H. Y., Wong, E., \& Wing, Y. K. (2005). SARS-related perceptions in Hong Kong. Emerging Infectious Diseases, 11(3), 417-424. 
Mak, I. W. C., Chu, C. M., Pan, P. C., Yiu, M. G. C., \& Chan, V. L. (2009). Long-term psychiatric morbidities among SARS survivors. General Hospital Psychiatry, 31, 318-326.

National Institute of Mental Health. (2019). Major depression. https:// www.nimh.nih.gov/health/statistics/major-depression.shtml. Accessed 3 June 2020.

Nickell, L. A., Crighton, E. J., Tracy, C. S., Al-Enazy, H., Bolaji, Y., Hanjrah, S., Hussain, A., Makhlouf, S., \& Upshur, R. E. G. (2004). Psychosocial effects of SARS on hospital staff: survey of a large tertiary care institution. Canadian Medical Association Journal, 170(5), 793-798.

Nolen-Hoeksema, S., Larson, J., \& Grayson, C. (1999). Explaining the gender difference in depressive symptoms. Journal of Personality and Social Psychology, 77(5), 1061-1072.

Peng, E. Y.-C., Lee, M.-B., Tsai, S.-T., Yang, C.-C., Morisky, D. E., Tsai, L.-T., Weng, Y.-L., \& Lyu, S.-Y. (2010). Population-based postcrisis psychological distress: an example from the SARS outbreak in Taiwan. Journal of the Formosan Medical Association, 109(7), 524-532.

Radloff, L. S. (1977). The CES-D Scale: a self-report depression scale for research in the general population. Applied Psychological Measurement, 1(3), 385-401.

Romans, S., Cohen, M., \& Forte, T. (2011). Rates of depression and anxiety in urban and rural Canada. Social Psychiatry and Psychiatric Epidemiology, 46, 567-575.

Slater, S. J., Christiana, R. W., \& Gustat, J. (2020). Recommendations for keeping parks and green space accessible for mental and physical health during COVID-19 and other pandemics. Preventing Chronic Disease, 17, E59.

Statistics Canada. (2019). Canadian Internet Use Survey. Released at 8: 30 a.m. Eastern time in The Daily, Tuesday, October 29, 2019. Statistics Canada catalogue no. 11-001-X.

Statistics Canada. (2020a). The Daily: Labour Force Survey, April 2020. https://www150.statcan.gc.ca/n1/daily-quotidien/200508/ dq200508a-eng.pdf. Accessed 14 August 2020.

Statistics Canada. (2020b). The Daily: Labour Force Survey, May 2020. https://www150.statcan.gc.ca/n1/daily-quotidien/200605/ dq200605a-eng.pdf. Accessed 14 August 2020.
Statistics Canada. (2020c). The Daily: impacts of COVID-19 on Canadian families and children (catalogue no. 11-001-X). https:// www150.statcan.gc.ca/n1/daily-quotidien/200709/dq200709a-eng. pdf. Accessed 13 August 2020.

Statistics Canada. (2020d). The Daily: Canadians' mental health during the COVID-19 pandemic. https://www150.statcan.gc.ca/n1/en/ daily-quotidien/200527/dq200527b-eng.pdf?st=e0j5ghhX. Accessed 17 August 2020.

Taylor, S., Landry, C. A., Paluszek, M. M., Fergus, T. A., McKay, D., \& Asmundson, G. J. G. (2020). COVID stress syndrome: concept, structure, and correlates. Depression and Anxiety, 37(8), 706-714.

TransUnion. (2020). Consumer financial hardship study: the impact due to COVID-19 in Canada. https://www.transunion.ca/financialhardship-study\#latest-report?itm_campaign=int-ca-20-718979-cafinancial-hardship-study-landing-page-week2-covid-19\&itm content=blog\&itm_medium=insight\&itm_source $=$ blog\&itmsource=blog. Accessed 13 August 2020.

Wang, C., Pan, R., Wan, X., Tan, Y., Xu, L., McIntyre, R. S., Choo, F. N., Tran, B., Ho, R., Sharma, V. K., \& Ho, C. (2020). A longitudinal study on the mental health of general population during the COVID19 epidemic in China. Brain, Behavior, and Immunity, 87, 40-48.

World Health Organization. (2020). Coronavirus disease (COVID-19): situation reports. https://www.who.int/emergencies/diseases/novelcoronavirus-2019/situation-reports. Accessed 1 September 2020.

Xu, J., Zheng, Y., Wang, M., Zhao, J., Zhan, Q., Fu, M., Wang, Q., Xiao, J., \& Cheng, Y. (2011). Predictors of symptoms of posttraumatic stress in Chinese university students during the 2009 H1N1 influenza pandemic. Medical Science Monitor, 17(7), PH60-PH64.

Yang, L., Zhao, Y., Wang, Y., Liu, L., Zhang, X., Li, B., \& Cui, R. (2015). The effects of psychological stress on depression. Current Neuropharmacology, 13(4), 494-504.

Zhou, X., Snoswell, C. L., Harding, L. E., Bambling, M., Edirippulige, S., Bai, X., \& Smith, A. C. (2020). The role of telehealth in reducing the mental health burden from COVID-19. Telemedicine and e-Health, 26(4), 377-379.

Publisher's note Springer Nature remains neutral with regard to jurisdictional claims in published maps and institutional affiliations. 